\title{
PENGARUH PENGGUNAAN DUAL BED CATALYTIC CONVERTER BERBAHAN TEMBAGA DAN KUNINGAN TERHADAP TINGKAT KEBISINGAN DAN PERFORMA MESIN
}

\author{
Syahrul Gunawan ${ }^{1}$, Warju ${ }^{2}$, Sinta Putri Anisa ${ }^{3}$, Emilda Dini Pratiwi ${ }^{4}$, Mahardika Dwi Saputra $^{5}$ \\ ${ }^{1}$ Program Studi S1 Teknik Mesin, Fakultas Teknik, Universitas Negeri Surabaya \\ J1. Ketintang, Ketintang, Kec. Gayungan, Kota SBY, Jawa Timur 60231 \\ Email: syahrul.17050754002@mhs.unesa.ac.id
}

\begin{abstract}
Abstrak
Seiring dengan meningkatnya aktivitas, manusia semakin memerlukan alat transportasi yang aman, nyaman dan memadai sebagai sarana pendukung mobilitas. Akibatnya, seiring perkembangan zaman jumlah arus lalu lintas dan jenis kendaraan yang menggunakan ruas-ruas jalan semakin bertambah. Hal ini menimbulkan masalah dibidang transportasi, salah satunya adalah masalah kebisingan yang ditimbulkan dari knalpot kendaraan. Oleh karena itu, upaya untuk mereduksi kebisingan dan tekanan balik dari muffler kendaraan perlu dilakukan. Salah satunya dengan menggunakan dual bed catalytic converter berbahan tembaga dan kuningan. Dual bed catalytic converter berfungsi sebagai pereduksi emisi sekaligus dapat merduksi kebisingan dan meningkatkan performa mesin. Tujuan penelitian ini adalah untuk mengetahui seberapa besar peningkatan performa mesin dan tingkat reduksi kebisingan dengan menggunakan dual bed catalytic converter berbahan tembaga dan kuningan pada sepeda motor Honda Vario Techno. Penelitian yang dilakukan adalah penelitian eksperimen. Analisis data menggunakan metode deskriftif kuantitatif. Berdasarkan hasil penelitian dapat disimpulkan bahwa penggunaan dual bed catalytic converter berbahan tembaga dan kuningan dapat meningkatkan, daya dan menurunkan tingkat kebisingan. Peningkatan torsi tertinggi pada catalytic kuningan-tembaga sebesar 16,70 \% didapatkan pada putaran $4000 \mathrm{rpm}$ dan catalytic tembaga-kuningan sebesar 10,06\% didapatkan pada putaran $8000 \mathrm{rpm}$. Peningkatan daya efektif catalytic Kuningan-Tembaga tertinggi sebesar 2,40\% didapatkan pada putaran 3000 rpm, sedangkan catalytic tembaga kuningan tertinggi sebesar $3,20 \%$. Selain itu dual bed catalytic converter berbahan tembaga dan kuningan dapat menurunkan tingkat kebisingan tertinggi pada catalytic Tembaga-Kuningan sebesar 3,08\% didapatkan pada putaran $4000 \mathrm{rpm}$ dan penurunan tingkat kebisingan tertinggi pada catalytic Kuningan-Tembaga sebesar 5.6\% pada putaran $4000 \mathrm{rpm}$.
\end{abstract}

Kata kunci: dual bed, catalytic converter, tembaga, kuningan.

\begin{abstract}
As activities increase, people increasingly need safe, comfortable and adequate means of transportation to support mobility. As a result, as time goes by the number of traffic flows and types of vehicles using road segments is increasing. This raises problems in the field of transportation, one of which is the problem of noise generated from vehicle exhaust. Therefore, efforts to reduce noise and back pressure from vehicle mufflers need to be done. One of them by using a dual bed catalytic converter made of copper and brass. The dual bed catalytic converter functions as a reducing emissions while reducing noise and improving engine performance. The purpose of this study was to determine how much increased engine performance and noise reduction levels using a dual bed catalytic converter made of copper and brass on a Honda Vario Techno motorcycle. The research conducted was experimental research. Data analysis uses quantitative descriptive method. Based on the results of this study concluded that the use of dual bed catalytic converters made from copper and brass can increase, power and reduce noise levels. The highest increase in torque at $16.70 \%$ catalytic brass was found at 4000 rpm and copperbrass catalytic at $10.06 \%$ obtained at $8000 \mathrm{rpm}$. The highest increase in the effective catalytic capacity of BrassCopper by $2.40 \%$ was found at $3000 \mathrm{rpm}$, while the highest catalytic copper brass was $3.20 \%$. In addition, the dual bed catalytic converter made from copper and brass can reduce the highest noise level on Copper-Kuningan catalytic by $3.08 \%$ obtained at $4000 \mathrm{rpm}$ and the highest noise level reduction on Brass-Copper catalytic by $5.6 \%$ at 4000 rpm rotation.
\end{abstract}

Key words: dual bed, catalytic converter, copper, brass.

12 Gunawan, Syahrul., dkk; Pengaruh Penggunaan Dual Bed Catalytic Converter Berbahan Tembaga Dan Kuningan Terhadap Tingkat Kebisingan Dan Performa Mesin 


\section{PENDAHULUAN}

Pada rentang 2005, perbandingan antara jumlah sepeda motor dan penduduk di Indoneisa diperkirakan mencapai 1:8 dan dari tahun ke tahun akan terus meningkat [1]. Pertumbuhan kendaraan bermotor yang tinggi tidak hanya didukung oleh jumlah penduduk Indonesia yang besar (240 juta), akan tetapi juga didukung oleh karakteristik orang Indonesia yang senang berganti-ganti kendaraan untuk menunjukkan eksistensi dan gengsi mereka di masyarakat [2]. Pertumbuhan tersebut akan menjadi lebih besar karena populasi kendaraan diproyeksikan untuk tumbuh mendekati 1.300 juta pada tahun 2030 [3].

Knalpot telah banyak digunakan untuk mengurangi kebisingan aliran di dalam saluran, seperti pada sistem knalpot kendaraan atau sistem ventilasi peralatan rumah tangga [4]. Prinsip kerja knalpot pada dasarnya digunakan untuk menurunkan tekanan dan temperatur gas buang serta mengurangi kebisingan yang ditimbulkan oleh ledakan pembakaran dari dalam ruang bakar dengan cara pembesaran ruangan agar gas buang mengalami ekspansi dan penurunan temperatur secara bertahap. Penurunan tekanan dan temperatur dapat terjadi karena amplitudo gelombang tekanan dan suara menjadi turun. Dengan demikian intensitas suara dan tekanan balik yang ditimbulkan akan menurun [5].

Secara umum, knalpot harus dirancang untuk memenuhi dua persyaratan berikut: (1) Knalpot harus meredam rentang frekuensi yang diinginkan, terutama rentang frekuensi rendah (2) Tekanan balik minimum, tekanan balik merupakan tekanan statis ekstra yang diberikan oleh knalpot pada engine melalui pembatasan aliran gas buang. Hal tersebut perlu dijaga agar tetap minimum, karena tekanan balik yang besar akan menghasilkan pengurangan efisiensi volumetrik dan tingkat konsumsi bahan bakar spesifik [6].

Kebisingan pada knalpot tersebut merupakan sebuah masalah yang sering dijumpai pada banyak perusahaan besar saat ini. Penggunaan mesin dan alat kerja yang mendukung proses produksi berpotensi menimbulkan suara kebisingan. Kebisingan adalah terjadinya bunyi yang tidak dikehendaki sehingga mengganggu atau membahayakan kesehatan (Kepmenkes No.1405/ MENKES/ SK/ XI/ 2002) [7]. Sedangkan menurut Keputusan Menteri Lingkungan Hidup KEPMEN LH No 48 Tahun 1996 Kebisingan merupakan bunyi yang tidak diinginkan dari usaha atau kegiatan dalam tingkat dan waktu tertentu yang dapat menimbulkan gangguan kesehatan manusia dan kenyamanan lingkungan [8]. Kebisingan juga dapat menyebabkan berbagai gangguan seperti gangguan fisiologis, gangguan psikologis, gangguan komunikasi dan ketulian. Selain itu kebisingan pada frekuensi rendah juga dapat mengganggu pengemudi dan penumpang [9].

Kebisingan pada knalpot akan berkaitan dengan performa mesin yang merupakan sebuah kinerja suatu mesin, dimana kinerja tersebut erat hubungannya dengan daya mesin yang dihasilkan serta daya guna dari mesin tersebut. Kinerja dari suatu mesin kendaraan umumnya ditunjukkan dalam tiga besaran, yaitu tenaga yang dapat dihasilkan, torsi yang dihasilkan, dan jumlah bahan bakar yang dikonsumsi. Tenaga bersih yang dihasilkan dari poros keluar mesin disebut "brake horse power" (Bhp). Tenaga total yang dapat dihasilkan dari piston mesin disebut "indicated horse power" (Ihp). Sebagian dari indicated horse power ini hilang akibat gesekan dan energi kelembaman dari massa yang bergerak yang disebut "friction horse power" [10].

Selain mengurangi kebisingan dalam perkembangannya, berbagai model knalpot juga berfungsi sebagai piranti untuk meningkatkan performa kendaraan bermotor, termasuk di dalamnya adalah knalpot jenis racing yang diproduksi oleh industri kecil [11]. Oleh karena itu, knalpot dapat dianggap sebagai perangkat yang dapat meningkatkan efisiensi energi sistem sekaligus mengurangi kebisingan [12].

Catalytic coverter merupakan teknologi untuk menurunkan kadar emisi dari kendaraan bermotor seperti karbon monoksida (CO), hidrokarbon (HC), dan nitrogen oksida $\left(\mathrm{NO}_{\mathrm{x}}\right)$ [13]. Selain itu, penambahan catalytic converter pada kendaraan mampu mereduksi kebisingan dan meningkatkan torsi daya perfroma kendaraan bermotor. Beberapa penelitian dilakukan untuk mendapatkan performa kendaraan yang tinggi dengan tetap memperhatikan polusi kebisingan pada kendaraan. Seperti penelitian catalytic converter selain mampu mengurangi emisi gas buang $\mathrm{CO}$ dan $\mathrm{HC}$ juga mampu meningkatkan performa mesin serta menurunkan tingkat kebisingan pada knalpot kendaraan [14]. Berlatar belakang dari masalah kebisingan pada kendaraan dan performa mesin maka dalam penelitian ini dilakukan eksperimen untuk mengetahui hasil tingkat kebisingan dan performa mesin motor Vario Techno 125 menggunakan dual bed catalytic converter berbahan dasar tembaga dan kuningan yang diletakan secara campur. Pengujian akan dibandingkan dengan knalpot standar, lalu knalpot dualbed catalytic converter bagian depan kuningan dan belakang tembaga (KT), dan kenalpot bagian depan dual bed catalytic converter berisi tembaga dan belakang kuningan (TK). Berdasarkan tiga knalpot tersebut akan diuji dan dicari data presentase penurunan kebisingan pada knalpot dengan penambahan catlytic converter KT dan TK, 
serta akan dicari data peningkatan performa mesin setelah menggunakan knalpot dengan penambahan catalytic converter tersebut.

\section{METODE PENELITIAN}

\section{Rancangan Penelitian}

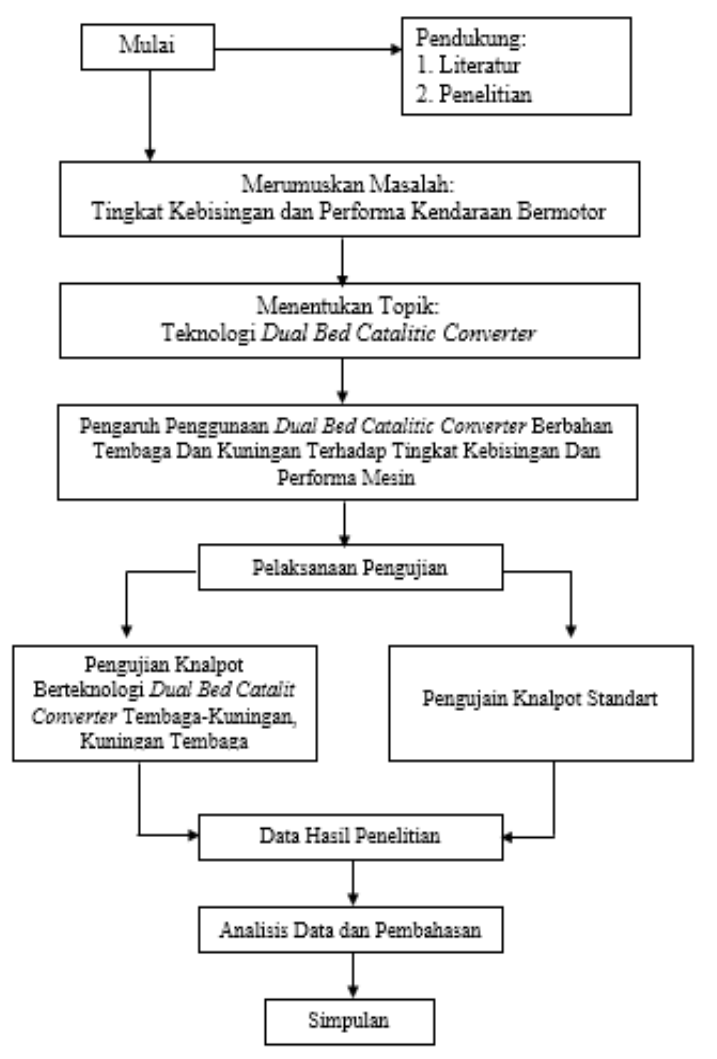

Gambar 1 Rancangan Penelitian

\section{Penelitian}

Untuk mengetahui hasil pengujian torsi, daya dan kebisingan pada knalpot yang diuji. Maka pada penelitian ini dilalakukan dengan menggunakan metode penelitian eksperimental.

Pengujian yang dilakukan meliputi pengujian tingkat kebisingan dan pengujian performa kendaraan seperti torsi dan daya. Prosedur pengujian tingkat kebisingan dilakukan menggunakan Sound Level Meter (SLM) yang dipasang pada jarak 0,5 $\mathrm{m} \pm$ $0,1 \mathrm{~m}$ dari titik sumbu pipa knalpot dengan membentuk sudut $45^{\circ} \pm 5^{\circ}$ dan tinggi SLM tidak kurang dari $0,2 \mathrm{~m}$ dari permukaan tanah. Motor dihubungkan dengan Rpm Counter dan pengujian yang dilakukan dengan mengukur kebisingan secara bertahap pada putaran mesin 1000 rpm sampai 9000 rpm dengan kenaikan 500 rpm setiap pengukurannya.
Pengujian torsi dan daya pada penelitian ini menggunakan pembebanan mesin dengan chassis dynamometer. Selanjutnya mengaktifkan beban pada chassis dynamometer dan memulai membuka throltle gas sampai pada kecepatan maksimal dan kemudian dilepaskan. Data operasi meliputi daya, putaran mesin dan torsi/beban akan langsung terbaca pada display chassis dynamometer secara real time.

\section{Instrumen}

1. Chasis Dynamometer

2. Rpm Counter

3. Sound Level Meter 4 in 1 Multi-Function

Environment Meter

\section{Obyek Peneltian}

Obyek yang digunakan dalam penelitian ini adalah Honda Vario Techno 125 CC Tahun 2013.

\section{Teknik Pengumpulan Data}

Teknik pengumpulan data dilakukan dengan referensi dan pengujian pada laboratorium performa mesin Fakultas Teknik Universitas Negeri Surabaya. Teknik pengumpulan data menggunakan metode pengujian sebagai berikut:

1. Pengukuran performa mesin berdasarkan standar SAE J1349 tentang Engine Power Test Code Spark Ignition and Compression Ignition - Net Power Rating.

2. Pengukuran tingkat kebisingan berdasarkan standar ISO/FDIS 5130:2006 (E) tentang Acoustics-Measurements of Sound Pressure Emitted by Stasionary Road Vehicles.

\section{Teknik Analisis Data}

Teknik analisis data menggunakan metode deskriptif, yaitu dengan mendeskriptifkan atau menggambarkan secara sistematis, faktual, dan akurat mengenai realita yang diperoleh selama pengujian. Data hasil penelitian yang diperoleh dimasukkan dalam tabel dan ditampilkan dalam bentuk grafik. Selanjutnya dideskriptifkan dengan kalimat sederhana sehingga mudah dipahami untuk mendapatkan jawaban dari permasalahan yang diteliti. Hal ini dilaksanakan untuk memberikan gambaran terhadap fenomena yang terjadi setelah diadakan penambahan catlytic converter pada saluran gas buang (knalpot) Vario Techno $125 \mathrm{CC}$. 


\section{HASIL DAN PEMBAHASAN}

\section{Desain Knalpot Variasi}

Knalpot variasi merupakan modifikasi dari knalpot standar yang ditambah dengan wadah dual bed catalytic converter yang didalamnya berisi catlytic converter berbahan dasar tembaga kuningan dan kuningan tembaga.

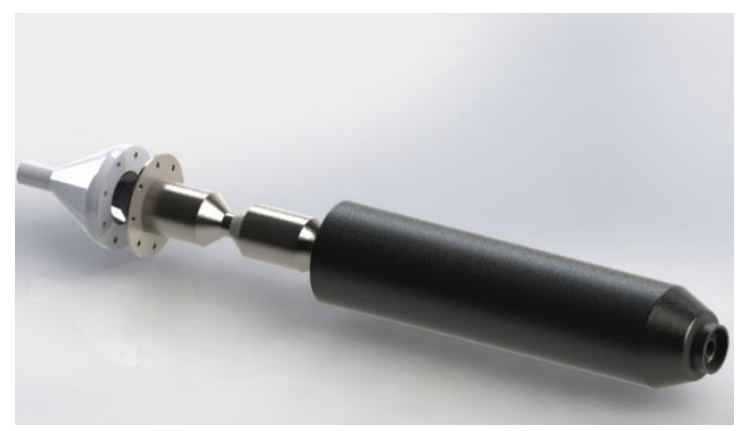

Gambar 2 Desain knalpot variasi

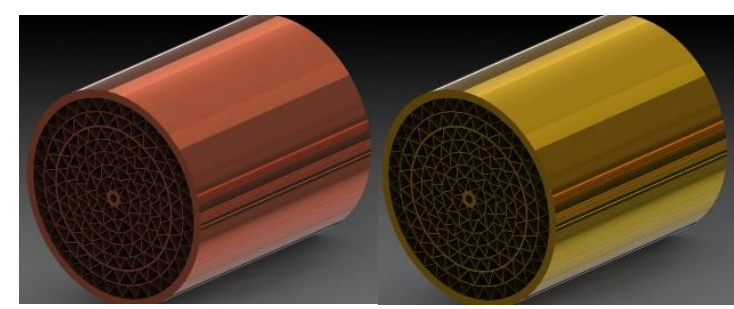

Gambar 3 Desain catalytic converter berbahan dasar tembaga dan kuningan

Catalytic converter yang digunakan diletakkan pada wadah dual bed secara campur, catalytic converter KT dan TK. Dua komposisi pada knalpot variasi ini diuji dan dibandingkan dengan knalpot standar untuk mengetahui apakah ada perbedaan terhadap kebisingan dan performa mesin pada motor Honda Vario Techno 125 setelah ditambahkan catalytic converter.

\section{HASIL PENGUJIAN}

Penelitian dilakukan dengan menggunakan metode eksperimen terhadap sepeda motor Honda Vario Techno $125 \mathrm{CC}$ yang menggunakan dual bed catalytic converter. Secara lengkap data-data yang didapatkan bisa dilihat pada grafik berikut.

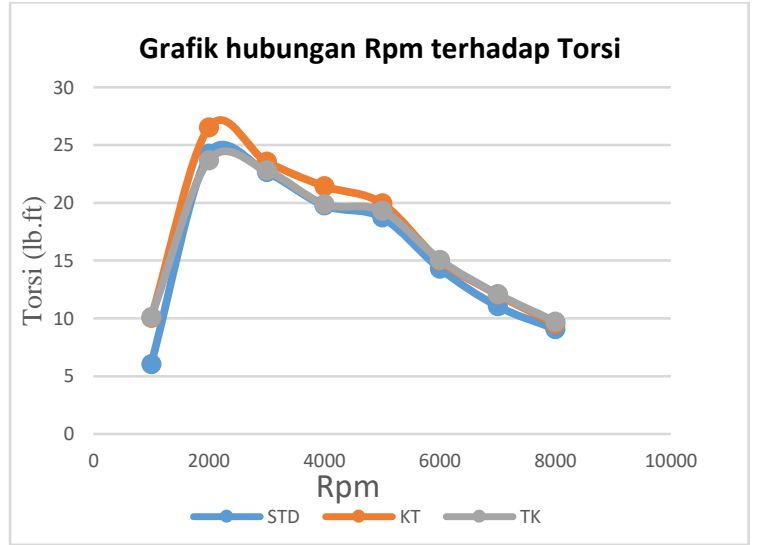

\section{Gambar 4 Grafik Hubungan antara putaran mesin terhadap torsi}

Berdasarkan grafik 1 penggunaan dual bed catalytic converter berbahan tembaga dan kuningan pada knalpot sepeda motor Honda Vario Techno 125 CC selain sebagai teknologi reduksi konsentrasi emisi $\mathrm{CO}$ dan $\mathrm{HC}$ juga dapat meningkatkan torsi yang dihasilkan. Peningkatan torsi tertinggi pada catalytic converter KT sebesar 16,70\% didapatkan pada putaran $4000 \mathrm{rpm}$ dan catalytic converter TK sebesar $10,06 \%$ didapatkan pada putaran $8000 \mathrm{rpm}$. Adanya penambahan dual bed catalytic converter berbahan tembaga dan kuningan di dalam wadah catalytic converter, torsi yang dihasilkan mesin cenderung naik hingga didapatkan torsi maksimal. Karena dengan penambahan dual bed catalytic converter, maka saluran gas buang akan memberikan tekanan balik yang lebih besar jika dibandingkan dengan knalpot standar. Tekanan balik ini akan dimanfaatkan untuk menaikkan torsi. Tekanan balik ini menyebabkan sebagian gas buang yang mengandung panas masuk ke dalam ruang bakar, sehingga efesiensi thermal mesin meningkat jika dibandingkan dengan efisiensi thermal mesin menggunakan knalpot standar.

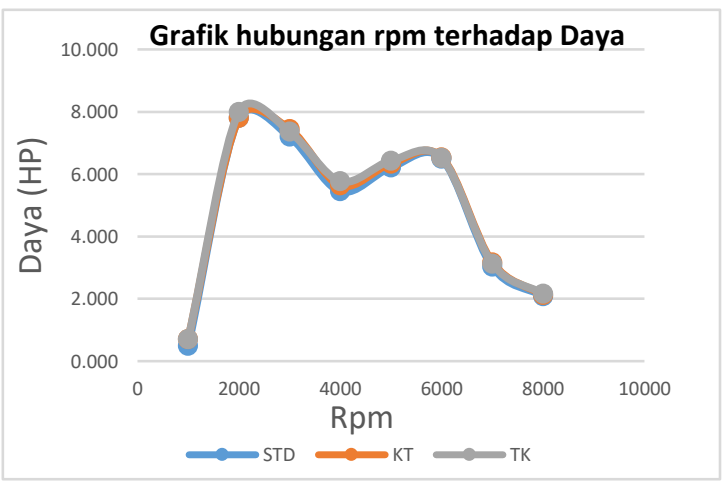

Gambar 5 Grafik Hubungan antara putaran mesin terhadap daya.

15 Gunawan, Syahrul., dkk; Pengaruh Penggunaan Dual Bed Catalytic Converter Berbahan Tembaga Dan Kuningan Terhadap Tingkat Kebisingan Dan Performa Mesin 
Berdasarkan grafik 2 penggunaan dual bed catalytic converter TK dan KT pada knalpot sepeda motor Honda Vario Techno 125 CC. Peningkatan daya efektif catalytic converter KT tertinggi sebesar 2,40\% didapatkan pada putaran $3000 \mathrm{rpm}$, sedangkan catalytic converter TK tertinggi sebesar $3,20 \%$. Meningkatnya daya efektif disebabkan karena torsi yang dihasilkan meningkat. Dampaknya daya efektif juga meningkat dibandingkan knalpot standar.

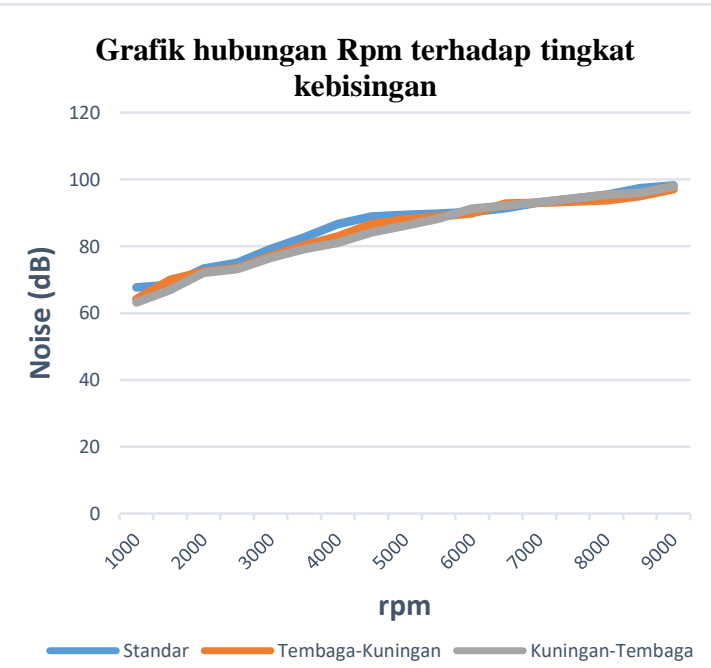

\section{Gambar 6 Grafik Hubungan antara putaran mesin terhadap tingkat kebisingan.}

Berdasarkan Grafik 3 penggunaan dual bed catalytic converter berbahan KT dan TK pada knalpot sepeda motor Honda Vario Techno 125 CC selain sebagai teknologi reduksi konsentrasi emisi CO dan HC juga dapat menurunkan tingkat kebisingan. Penurunan kebisingan yang terjadi disebabkan karena tekanan gas buang pada knalpot ekperimen diturunkan dengan adanya dual bed catalytic converter berbahan tembaga dan kuningan yang dimasukan kedalam wadah catalytic converter, sehingga gas sisa hasil pembakaran dalam ruang bakar yang keluar melalui pipa utama dapat diredam secara sempurna oleh dual bed catalytic converter berbahan KT dan TK yang terdapat dalam pipa utama. Dampaknya tingkat kebisingan pada knalpot berteknologi dual bed catalytic converter mengalami penurunan jika dibandingkan dengan knalpot standar. Penurunan tingkat kebisingan tertinggi pada catalytic converter TK sebesar 3,08 \% didapatkan pada putaran $4000 \mathrm{rpm}$ dan penurunan tingkat kebisingan tertinggi pada catalytic converter KT sebesar 5.6\% pada putaran $4000 \mathrm{rpm}$.

\section{KESIMPULAN}

Berdasarkan hasil analisis data dan pembahasan dapat disimpulkan bahwa knalpot sepeda motor Honda Vario Techno $125 \mathrm{CC}$ yang menggunakan dual bed catalytic converter berbahan tembaga dan kuningan pada knalpot eksperimen dapat meningkatkan torsi dan daya yang dihasilkan. Peningkatan torsi tertinggi pada catalytic converter KT sebesar 16,70\% didapatkan pada putaran 4000 rpm dan catalytic converter TK sebesar 10,06\% didapatkan pada putaran $8000 \mathrm{rpm}$. Peningkatan daya efektif catalytic converter KT tertinggi sebesar 2,40 $\%$ didapatkan pada putaran $3000 \mathrm{rpm}$, sedangkan catalytic converter TK tertinggi sebesar 3,20\%. Selain itu dual bed catalytic converter berbahan TK dan KT pada knalpot sepeda motor Honda Vario Techno $125 \mathrm{CC}$ dapat menurunkan tingkat kebisingan tertinggi pada catalytic converter TK sebesar 3,08\% didapatkan pada putaran $4000 \mathrm{rpm}$ dan penurunan tingkat kebisingan tertinggi pada catalytic converter KT sebesar $5.6 \%$ pada putaran $4000 \mathrm{rpm}$. Berdasarkan hasil pengujian secara keseluruhan, penggunaan catalytic converter KT memiliki kemampuan yang baik dalam meningkatkan torsi dan mereduksi kebisingan dibandingkan catalytic converter TK. Sedangkan peningkatan daya, catalytic converter TK mampu memberikan hasil yang lebih baik dibandingkan dengan catlytic converter KT.

\section{UCAPAN TERIMA KASIH}

Ucapan terima kasih diberikan kepada LPPM Universitas Negeri Surabaya selaku penyelenggara dan pemberi dana dalam kegiatan Penelitian Mahasiswa.

\section{DAFTAR PUSTAKA}

[1] Ismiyati, D. Marlita, and D. Saidah, "Pencemaran Udara Akibat Emisi Gas Buang Kendaraan Bermotor," J. Manaj. Transp. Logistik, vol. 01, no. 03, pp. 241-248, 2014.

[2] M. H. Anshari, K. D. Artika, and A. Kuswoyo, "Analisa Pengukuran Tingkat Kebisingan Sepeda Motor Berdasarkan Rpm Dan Jumlah Kendaraan," J. Elem., vol. 5, no. 1, p. 07, 2018, doi: 10.34128/je.v5i1.67.

[3] R. Manojkumar, S. Haranethra, M. Muralidharan, and A. Ramaprabhu, "I.C. Engine emission reduction using catalytic converter by replacing the noble catalyst and using copper oxide as the catalyst," Mater. Today Proc., no. xxxx, 2020, doi: 10.1016/j.matpr.2020.02.804. 
[4] J. K. Lee, K. S. Oh, and J. W. Lee, "Methods for evaluating in-duct noise attenuation performance in a muffler design problem," J. Sound Vib., vol. 464, p. 114982, 2020, doi: 10.1016/j.jsv.2019.114982.

[5] E. F. Obert, "Internal combustion engines and air pollution," 1973.

[6] T. Yasuda, C. Wu, N. Nakagawa, and K. Nagamura, "Predictions and experimental studies of the tail pipe noise of an automotive muffler using a one dimensional CFD model," Appl. Acoust., vol. 71, no. 8, pp. 701-707, 2010, doi: 10.1016/j.apacoust.2010.03.001.

[7] "Keputusan Menteri Kesehatan Republik Indoneisa Nomor 1405/MENKES/SK/XI/2002," 2002.

[8] Kementerian Lingkungan Hidup, "Keputusan Kementerian Lingkungan Hidup Tentang Baku Tingkat Kebisingan,” Jakarta, 1996.

[9] H. Shao, H. He, Y. Chen, X. Tan, and G. Chen, "A tunable metamaterial muffler with a membrane structure based on Helmholtz cavities," Appl. Acoust., vol. 157, p. 107022, 2020, doi: 10.1016/j.apacoust.2019.107022.
[10]M. Aris, "Penggunaan $\mathrm{Cu}$ Murni di Exhaust Muffler dalam Upaya Pengurangan Emisi Gas Buang," Institut Sepuluh November, 2005.

[11]E. Subandono, Sukoco, and M. Syamsiro, "Analisis Tingkat Kebisingan Knalpot Sepeda Motor Produk Industri Kecil," J. Mek. dan Sist. Termal, vol. 2, no. 2, pp. 21-26, 2017.

[12]S. Oh, S. Wang, and S. Cho, "Topology optimization of a suction muffler in a fluid machine to maximize energy efficiency and minimize broadband noise," J. Sound Vib., vol. 366, pp. 27-43, 2016, doi: 10.1016/j.jsv.2015.10.022.

[13]H. Purnomo, “Analisa Pengaruh Knalpot Knalpot Catalytic Converter dengan Katalis Tembaga $(\mathrm{Cu})$ Berlapis Mangan ( $\mathrm{Mn})$ terhadap Gas Buang Honda Supra X 100 cc," J. Ilm. ITS, vol. 1, pp. 1-9, 2012.

[14]S. D. Sulistiyono and Warju, "Unjuk Kemampuan Metalic Catalytuc Converter Berbahan Dasar Kuningan Berlapis Nikel Terhadap Performa Mesin, Reduksi Emisi Gas Buang, Dan Tingkat Kebisingan Sepeda Motor Yamaha V-IXION Tahun 2011," J. Tek. Mesin, vol. 02, pp. 1-10, 2014. 